ISSN No. 0974-035X

An indexed refereed \& peer-reviewed journal of higher education

Towards Excellence

UGC-HUMAN RESOURCE DEVELOPMENT CENTRE

Gujarat University, Ahmedabad-380009, Gujarat, India

\title{
RELATION BETWEEN OBESITY AND THYROID STATUS IN GERIATRIC INDIVIDUALS OF AHMEDABAD CITY
}

\author{
Ms. Jayshree N. Tolani \\ Dr. Rosy Lekharu \\ Dr. Nitinkumar D. Shah
}

\begin{abstract}
Background: Hypothyroidism is a significant possibility factor for cardiovascular diseases. And autoimmune thyroiditis (AIT) is the prominent reason of hypothyroidism. Recent studies exhibited that even AIT patients with euthyroidism still had an increased number of premature atherosclerotic lesions. However, the specific procedure is not yet established. This study aimed to investigate the relation of thyroid status and obesity risk factors in geriatric individuals.
\end{abstract}

Methods: The present study was carried out at a tertiary care centre in Ahmedabad. A total of 1000 geriatric individuals (aged more than 60 years) were included, which were randomly selected from the O.P.D. and indoor patients.

Results: The geriatric patients were found to have significantly lower FT3 and FT4 levels with higher TSH and antithyroid peroxidase antibodies (Anti TPO) levels. Obesity was found to have a positive correlation with TSH and Anti TPO levels. Regression analysis also demonstrated that the Anti TPO level was one of the influencing factors for Obesity and Cholesterol.

Conclusion: The Anti TPO level is positively associated with Obesity.

Keywords: Obesity, Anti TPO level, thyroid status, geriatric individuals.

\section{Introduction}

The thyroid is an endocrinal, butterfly-molded, and largest organ in the neck which synthesises and stores hormones that assist in the control of blood circulation, pulse, and body temperature and furthermore help in the direction of development and rate of compound responses (digestion) 
Towards Excellence: An Indexed, Refereed \& Peer Reviewed Journal of Higher Education / Ms. Jayshree Tolani, Dr. Rosy Lekharu \& Dr. Nitinkumar Shah/ Page 94-101

in the body (How does the thyroid gland work?, IQWiG, 2018). The thyroid organ made up from follicular cells which produce two noteworthy hormones - T3 (Triiodothyronine) and T4 (Tetraiodothyronine or Thyroxine) and few parafollicular cells (C - cells) produces hormone called "Calcitonin" which helps in the direction of calcium homeostasis (Johns Hopkins Medicine. The thyroid gland). T4 constitutes $80-95 \%$ of total hormones synthesised by the Thyroid, but it is less dynamic, compared to T3 which is found in less quantity (about $5-20 \%$ ) organically more dynamic than T4 (Thyroid hormone production and function, Michigan Medicine, 2018).Thyroid organ cells have receptor site, Thyroid-stimulating Hormones (TSH) discharged by anterior pituitary connected with these receptors, and the cells invigorated to create and discharge thyroid hormones. If more T3 and T4 are required to the body, at that point more amount of TSH is created, and when less T4 and T3 are required, at that point little amount of TSH is delivered by pituitary organ (Dai G et al., 1996). TSH directs the iodide take-up by sodium/iodide symporters; the means are important for typical thyroid hormone combination and discharge (Shahid Muhammad A. et al. 2020). Available for use larger part of T4 and T3 are bound with bearer proteins, which helps in transportation (Wu Alan HB et al., 1999). Just a little division stays unbound known as free T3 (fT3) and free t4 (fT4) in the flow, and when it ventured into the required tissue, it enters inside the cells by special transport channels and cytoplasm is where changes of T4 to T3 occur, for the most part in liver, pituitary, and kidney. Typically, about $0.03 \% \mathrm{~T} 4$ and $0.5 \% \mathrm{~T} 3$ were found in unbound structure, and just free structure can tie with explicit hormone receptor (Billic Komarica et al. 2012). Hypothyroidism, hyperthyroidism, thyroiditis, goitre, hubs, and tumor of thyroid organ are the common disorders associated with the Thyroid gland (Greenspan Francis et al., 2001). Hypothyroidism is a clinical disorder due to inadequacy of thyroid hormones which prompts moderate downregulation of metabolic procedures (Rizos C. V.. et al., 2011). The instances of hypothyroidism were more common in females and occurrence is expanded with age (Proces S. et al., 2001). Immune system interminable lymphocytic thyroiditis is the most widely recognized reason for hypothyroidism in Australia. It is generally found in diabetic patients (Michalek Arthur M. et al, 2000, Helfand Mark 2004). It is corpulence like neurotic condition, related with lipid digestion issue, and prompts dyslipidaemia (one of the significant hazard elements of coronary maladies) (Shilpashree M. et al., 2014). Hypothyroidism is related with cardiovascular hazard factors, and if untreated, it can lead to atherosclerosis (https://www.ncbi.nlm.nih.gov/books/NBK83496/). Subclinical hypothyroidism $(\mathrm{SH})$ is characterized by slightly elevated TSH level (5 - 10 
Towards Excellence: An Indexed, Refereed \& Peer Reviewed Journal of Higher Education / Ms. Jayshree Tolani, Dr. Rosy Lekharu \& Dr. Nitinkumar Shah/ Page 94-101

$\mathrm{mIU} / \mathrm{L}$ ), normal thyroid hormone levels and no clinical signs and manifestations. (Canaris Gay J. et al. 2000). Impact of SH is not clearly known yet, but different examinations revealed that it is related with abnormal amounts of low-density lipoprotein (LDL), all out cholesterol (TC), and cardiovascular infection patients (Rizos C. V. et al. 2011). Hypothyroidism was determined by diminished serum FT4 to have increased TSH levels.

\section{MATERIALS AND METHODS}

A total of 1000 obese and non-obese geriatric individuals were recruited from a tertiary care centre. For every individual Anti TPO, T3, T4, TSH, FreeT3 (FT3), FreeT4 (FT4), Cholesterol, Age (in completed years), Gender, Height and Weight was recorded. BMI was calculated for everyone using the formula BMI = weight $(\mathrm{kg}) /\{\text { height }(\mathrm{m})\}^{2}$ and then individuals were bifurcated according to the Asiatic classification of WHO. The current WHO BMI cut-off points for BMI are $<16 \mathrm{~kg} / \mathrm{m}^{2}$ (severe underweight), $16.0-16.9 \mathrm{~kg} / \mathrm{m}^{2}$ (moderate underweight), $17.0-18.49 \mathrm{~kg} / \mathrm{m}^{2}$ (underweight), 18.5-24.9 kg/m² (normal range), $\geq 25$ (overweight), $25-29.9 \mathrm{~kg} / \mathrm{m}^{2}$ (pre-obese), $\geq 30 \mathrm{~kg} / \mathrm{m}^{2}$ (obesity), $30-34.9 \mathrm{~kg} / \mathrm{m}^{2}$ (obese class 1 ), $35-39.9 \mathrm{~kg} / \mathrm{m}^{2}$ (obesity class 2 ), $\geq 40 \mathrm{~kg} / \mathrm{m}^{2}$ (obesity class 3 ).

The geriatric patients, who were willing to participate in the study, were only enrolled in the study. Participants who were having high cholesterol levels, abnormal TSH, TPOAb were interviewed regarding knowledge and practice regarding their food habits through pre-formed semi structured questionnaire.

Data was tabulated in Microsoft Excel and analyzed using IBM Corp. Released 2011. IBM SPSS Statistics for Windows, Version 20.0. Armonk, New York, and Microsoft Excel 2007.

\section{Results}

The types of data to be analyzed were 1000 geriatric patients whose diagnosis and measurements were taken directly. The samples were examined, separately and pooled. Table 1 displays the mean and their respective standard deviation values of eight parameters resulting from the data which were used to produce a series of discriminant functions and logistic regression for BMI determination. BMI was also determined using discriminant function and logistic regression in the pooled sample (Table 4). Further, the collected data were checked for their accuracy and reliability with the traditional equations of discriminant function and logistic regression. Table 5 
Towards Excellence: An Indexed, Refereed \& Peer Reviewed Journal of Higher Education / Ms. Jayshree Tolani, Dr. Rosy Lekharu \& Dr. Nitinkumar Shah/ Page 94-101

illustrates the accuracy level of males and females when the values of thyroid status parameters and other demographic variables were placed in the formulated equations. The results were considered statistically significant at $5 \%$ level of significance i.e.., p-value $<0.05$.

Table 1:Clinical characteristics of the Geriatric Patients

\begin{tabular}{|c|c|c|c|c|c|}
\hline \multicolumn{2}{|l|}{ Gender } & $\mathrm{N}$ & Mean & Std. Deviation & $\begin{array}{l}\text { t-test } \\
\text { p-value }\end{array}$ \\
\hline \multirow{2}{*}{ Age* } & Male & 166 & 68.301 & 4.070 & \multirow{2}{*}{$0.034^{*}$} \\
\hline & Female & 834 & 69.0263 & 3.592 & \\
\hline \multirow{2}{*}{ ANTI TPO* } & Male & 166 & 187.698 & 342.768 & \multirow{2}{*}{$0.006^{*}$} \\
\hline & Female & 834 & 110.250 & 245.376 & \\
\hline \multirow{2}{*}{ CHOLESTEROL } & Male & 166 & 156.086 & 78.280 & \multirow{2}{*}{0.130} \\
\hline & Female & 834 & 146.000 & 77.373 & \\
\hline \multirow{2}{*}{$\mathrm{T} 3$} & Male & 166 & 5.573 & 13.482 & \multirow{2}{*}{0.685} \\
\hline & Female & 834 & 6.039 & 13.533 & \\
\hline \multirow{2}{*}{$\mathrm{T} 4$} & Male & 166 & -6.676 & 20.129 & \multirow{2}{*}{0.730} \\
\hline & Female & 834 & -7.267 & 20.272 & \\
\hline \multirow{2}{*}{$\mathrm{TSH}$} & Male & 166 & -1.047 & 5.735 & \multirow{2}{*}{0.433} \\
\hline & Female & 834 & -1.444 & 6.888 & \\
\hline \multirow{2}{*}{ FT3* } & Male & 166 & -.228 & 1.481 & \multirow{2}{*}{$0.030 *$} \\
\hline & Female & 834 & 0.040 & 1.224 & \\
\hline \multirow{2}{*}{ FT4* } & Male & 166 & -2.622 & 6.242 & \multirow{2}{*}{$0.003 *$} \\
\hline & Female & 834 & -1.115 & 4.126 & \\
\hline \multirow{2}{*}{ BMI } & Male & 166 & 29.57 & 3.997 & \multirow{2}{*}{0.123} \\
\hline & Female & 834 & 30.09 & 3.842 & \\
\hline
\end{tabular}

Table1 shows the characteristics of the Geriatric Patients. The clinical parameters were bifurcated with respect to gender. Student's t-test was used to test the significant difference between the genders. Age, Anti TPO, FT3, FT4 differ significantly for males and females while there was no significant difference seen in cholesterol levels, T3, T4, TSH levels and BMI.

Table 2: Correlation between Thyroid Function, Thyroid Antibody and Clinical Parameters

\begin{tabular}{|l|l|l|l|l|l|l|l|}
\hline \multicolumn{2}{|l|}{ Correlations } & T3 & T4 & TSH & FT3 & FT4 & $\begin{array}{l}\text { Anti } \\
\text { TPO }\end{array}$ \\
\hline \multirow{2}{*}{ Age } & $\begin{array}{l}\text { Pearson } \\
\text { Correlation }\end{array}$ & $0.114^{* *}$ & $-0.093^{* *}$ & $-0.224^{* *}$ & $0.295^{* *}$ & $0.377^{* *}$ & $-0.396^{* *}$ \\
\cline { 2 - 8 } & p-value & 0.000 & 0.003 & 0.000 & 0.000 & 0.000 & 0.000 \\
\hline \multirow{2}{*}{ BMI } & $\begin{array}{l}\text { Pearson } \\
\text { Correlation }\end{array}$ & $-0.620^{* *}$ & $0.566^{* *}$ & $0.592^{* *}$ & $-0.646^{* *}$ & $-0.478^{* *}$ & $0.565^{* *}$ \\
\cline { 2 - 9 } & p-value & 0.000 & 0.000 & 0.000 & 0.000 & 0.000 & 0.000 \\
\hline
\end{tabular}


Towards Excellence: An Indexed, Refereed \& Peer Reviewed Journal of Higher Education / Ms. Jayshree Tolani, Dr. Rosy Lekharu \& Dr. Nitinkumar Shah/ Page 94-101

\begin{tabular}{|l|l|l|l|l|l|l|l|}
\multirow{2}{*}{ CHOLESTEROL } & $\begin{array}{l}\text { Pearson } \\
\text { Correlation }\end{array}$ & $-0.727^{* *}$ & $0.689^{* *}$ & $0.776^{* *}$ & $-0.766^{* *}$ & $-0.548^{* *}$ & $0.594^{* *}$ \\
\cline { 2 - 8 } & p-value & 0.000 & 0.000 & 0.000 & 0.000 & 0.000 & 0.000 \\
\hline
\end{tabular}

**. Correlation is significant at the 0.01 level (2-tailed).

\section{Table 2 shows}

1. The association of age with T3, FT3, FT4 was positive and to that of T4, TSH and Anti TPO was negative.

2. The association of BMI with T3, FT3, FT4 was negative while with T4, TSH, Anti TPO was positive.

3. The association of cholesterol with T3, FT3, FT4 was negative, while association was positive with TSH, Anti TPO.

Table 3: Discriminant function and logistic regression for the obesity determination.

\begin{tabular}{|c|c|c|c|c|c|}
\hline Sr. No. & Group & $\begin{array}{l}\text { P- } \\
\text { value }\end{array}$ & Equation & Score & $\begin{array}{l}\text { Accuracy } \\
(\%)\end{array}$ \\
\hline 1 & $\begin{array}{l}\text { Logistic } \\
\text { regression }\end{array}$ & 0.000 & $\begin{array}{l}-245.707 \text { (Constant)* } \\
-2.622 \mathrm{~T} 3 \\
-2.448 \mathrm{~T}^{*} \\
+3.990 \mathrm{TSH}^{*} \\
+304.834 \mathrm{FT} 3 \\
-36.254 \mathrm{FT} 4 \\
-2.00 \mathrm{TPOAb}^{*} \\
+0.516 \mathrm{Cholesterol}^{*} \\
++16.254 \text { gender } \\
+6.84 \text { age }\end{array}$ & $0^{\mathrm{a}}$ & $80.5 \%$ \\
\hline 2 & $\begin{array}{l}\text { Discriminant } \\
\text { function }\end{array}$ & 0.000 & $\begin{array}{l}\text { - } 223.363 \text { (Constant)* } \\
+0.957 \mathrm{~T}^{*} \\
-0.072 \mathrm{~T}^{*} \\
+0.266 \mathrm{TSH}^{*} \\
-7.308 \mathrm{FT}^{*} \\
+0.459 \mathrm{FT}^{*} \\
+0.010 \mathrm{TPOAb}^{*} \\
+0.124 \mathrm{Cholesterol}^{*} \\
+4.385 \text { gender } \\
+6.096 \text { age }\end{array}$ & $-1.9635^{b}$ & $97.9 \%$ \\
\hline
\end{tabular}

a. In gender, female group is transformed to " 1 " and male group is transformed to " 0 ". If the value of the logistic function is positive, we can predict that the person is obese and if the value is negative, we predict non-obese individual. 
Towards Excellence: An Indexed, Refereed \& Peer Reviewed Journal of Higher Education / Ms. Jayshree Tolani, Dr. Rosy Lekharu \& Dr. Nitinkumar Shah/ Page 94-101

b. If the discriminant score is $<-1.9635$ we predict the individual as non-obese and if the value is $>-1.9635$ we predict the individual as obese.

\section{Discussion}

BMI determination is very important for prevention as well as identification of many diseases like obesity, cardiovascular diseases, hypertension, hypothyroidism etc . in medical field.

The present work showed the accuracy for estimating obesity using multivariate analysis through both discriminant function as well as logistic regression equations of geriatric patients. The accuracy of discriminant function is better compared to that of logistic function.

Though in Table 2, Age, BMI (Quantitative Actual) and Cholesterol showed significant correlation with thyroid functions and thyroid antibody, age and gender does not play a significant role neither in discriminant function nor logistic regression analysis ( Table 3).

\section{Conclusion :-}

From the present study it was concluded that the mean values of age, T3, FT3, FT4 and BMI in females were greatest when compared to that of males. So, females have higher probability of obesity and other diseases compared to that of males. The equations derived can be used for the determination of obesity with the highest average accuracy of $97.5 \%$ using deterministic function.

As the participants included in the study were geriatric, age and gender did not play any significant role in obesity determination. Anti TPO, Cholesterol, T3, FT4 have a significant positive correlation with BMI. T4, TSH and FT3 have a negative relation with BMI.

Health education regarding good eating practices was given to each participant for the betterment of their health and for prevention of diseases like cardiovascular, goitre, hubs, and hypertension. 
Towards Excellence: An Indexed, Refereed \& Peer Reviewed Journal of Higher Education / Ms. Jayshree Tolani, Dr. Rosy Lekharu \& Dr. Nitinkumar Shah/ Page 94-101

\section{References}

How does the thyroid gland work? Institute for Quality and Efficiency in Health Care (IQWiG). Updated April 19, 2018.

Johns Hopkins Medicine. The thyroid gland

Michigan Medicine. Thyroid hormone production and function. Updated November 6, 2018.

Dai, G., et al. "The mediator of thyroidal iodide accumulation: the sodium/iodide symporter." Handbook of biological physics. Vol. 2. North-Holland, 1996. 343-368. doi:10.1016/s1383-8121(96)80056-X

Shahid, Muhammad A., Muhammad A. Ashraf, and Sandeep Sharma. "Physiology, thyroid hormone." StatPearls

[Internet] (2020).

.https://www.ncbi.nlm.nih.gov/books/NBK500006/.

Wu, Alan HB, et al. "National Academy of Clinical Biochemistry Standards of Laboratory Practice: recommendations for the use of cardiac markers in coronary artery diseases." Clinical chemistry 45.7 (1999): 1104-1121.

Billic-Komarica, Edina, Amela Beciragic, and Dzelaludin Junuzovic. "The importance of HbA1c control in patients with subclinical hypothyroidism." Materia socio-medica 24.4 (2012): 212.

Greenspan, Francis S., and David G. Gardner. "Basic and clinical endocrinology." (2001).

Rizos, C. V., M. S. Elisaf, and E. N. Liberopoulos. "Effects of thyroid dysfunction on lipid profile." The open cardiovascular medicine journal 5 (2011): 76.

Proces, S., et al. "Minor alterations in thyroid-function tests associated with diabetes mellitus and obesity in outpatients without known thyroid illness." Acta Clinica Belgica 56.2 (2001): 86-90.

Michalek, Arthur M., Martin C. Mahoney, and Donald Calebaugh. "Hypothyroidism and diabetes mellitus in an American Indian population." Journal of family practice 49.7 (2000): 638-638.

Helfand, Mark. "Screening for subclinical thyroid dysfunction in nonpregnant adults: a summary of the evidence for the US Preventive Services Task Force." Annals of internal medicine 140.2 (2004): 128-141.

Shilpashree, M., and B. Ravi. "Serum lipoprotein (a) and lipid profile in hypothyroidism." J Clin Biomed Sci 4 (2014): 235-9. 
Towards Excellence: An Indexed, Refereed \& Peer Reviewed Journal of Higher Education / Ms. Jayshree Tolani, Dr. Rosy Lekharu \& Dr. Nitinkumar Shah/ Page 94-101

https://www.ncbi.nlm.nih.gov/books/NBK83496/

Canaris, Gay J., et al. "The Colorado thyroid disease prevalence study." Archives of internal medicine 160.4 (2000): 526-534.

Rizos, C. V., M. S. Elisaf, and E. N. Liberopoulos. "Effects of thyroid dysfunction on lipid profile." The open cardiovascular medicine journal 5 (2011): 76

\section{Jayshree N. Tolani}

PhD Student, Department of Statistics, School of Sciences, Gujarat University, Ahmedabad

E-mail: jayu594@gmail.com

\&

Dr. Rosy Lekharu

Professor, Department of Biochemistry, GCS Medical College Hospital and Research Centre, Gujarat University, Ahmedabad, Gujarat

E-mail: drrosyl@gmail.com, Contact No. 919537729599

\&

Dr. Nitinkumar D. Shah

Head, Department of Statistics, Prin. M. C. Shah Commerce College, Navgujarat Campus, Opp. Gujarat Vidhyapith, Ashram Road, Ahmedabad E-mail: drndshah01@gmail.com 